\title{
Ruthenium tetroxide staining of polybutylene terephthalate (PBT) and polyisobutylene-b-PBT segmented block copolymers
}

\author{
Helena Janik*, Eric Walch and Reinoud J. Gaymans $\dagger$ \\ Department of Chemical Technology, University of Twente, PO Box 217, 7500 AE Enschede, \\ The Netherlands \\ (Received 5 December 1991; revised 7 February 1992)
}

A ruthenium tetroxide $\left(\mathrm{RuO}_{4}\right)$ staining method has been evaluated for segmented polyisobutylene- $b$ polybutylene terephthalate (PIB- $b$-PBT). Solution cast films and melt pressed samples have been studied. For comparison PBT has also been studied. PBT and PIB- $b$-PBT could be stained with $\mathrm{RuO}_{4}$ at room temperature. The observed structures on the PBT and PIB-b-PBT films were spherulitic with lamellae. In some regions in the PIB- $b$-PBT films large scale phase separation was observed. In the melt pressed PIB- $b$-PBT samples the spherulitic and lamellar structures were less well developed. The PBT segments appeared to have crystallized out in bundles and the PIB phase was present as microspheres with diameters of $3-6 \mathrm{~nm}$.

(Keywords: polyisobutylene; polybutylene terephthalate; segmented block copolymer; staining; ruthenium tetroxide; structure)

\section{Introduction}

Segmented telechelic polyisobutylene- $b$-polybutylene terephthalate (PIB- $b$-PBT) is a thermoplastic elastomer. Segmented block copolymers are built from soft and hard segments and have a lamellar structure ${ }^{1}$.

Segmented block copolymers, like polyether-polyesters, are two-phase materials with one amorphous and one crystalline phase. The structure is like that in semicrystalline homopolymers, namely spherulitic with lamellae ${ }^{1}$.

The block copolymer PIB- $b$-PBT (30/70) has two glass transitions and a melting temperature and is thus a three-phase system ${ }^{2,3}$. The lowest glass transition at $-65^{\circ} \mathrm{C}$ is from the PIB phase, the glass transition at $35^{\circ} \mathrm{C}$ is from the amorphous PBT-rich phase and the melting temperature at $210^{\circ} \mathrm{C}$ is from the crystalline PBT phase. The crystallinity of the PBT phase is in the order of $30 \%$. The volume ratios are : PBT crystalline $20 \%$, PBT amorphous $40 \%$ and PIB $40 \%$.

To study the relationship between the structure and properties of these materials the polymer morphology was studied using transmission electron microscopy (TEM). Osmium tetroxide $\left(\mathrm{OsO}_{4}\right)$ is the most commonly used chemical for staining polymers with some degree of unsaturation ${ }^{4-6}$. PIB and its isomers are difficult to stain with $\mathrm{OsO}_{4}$ due to their high degree of saturation. Ruthenium tetroxide $\left(\mathrm{RuO}_{4}\right)$ is a comparatively new staining agent and is known ${ }^{7-10}$ to be a stronger oxidizing and a more versatile agent than $\mathrm{OsO}_{4}$. $\mathrm{RuO}_{4}$ staining has successfully been used for segmented copolyesters $^{11}$, polyesterurethanes ${ }^{12.13}$ and polyetherurethanes ${ }^{14}$. One method of staining with $\mathrm{RuO}_{4}$ starts from ruthenium trichloride and sodium hypochlorite ${ }^{15}$. It was found that in situ $\mathrm{RuO}_{4}$ obtained in this way appears to be at least as effective as commercial $\mathrm{RuO}_{4}$.

* On leave from the Technical University of Gdansk, Institute of Organic and Food Chemistry and Technology, 80-952 Gdansk, Poland + To whom correspondence should be addressed

0032-3861/92/163522-03

(C) 1992 Butterworth-Heinemann Ltd.

3522 POLYMER, 1992, Volume 33, Number 16
The aim of this study is to evaluate the staining of PBT and segmented PIB-PBT and to study the structure of PIB- $b$-PBT segmented block copolymers using $\mathrm{RuO}_{4}$ as the staining agent.

\section{Experimental}

Materials. PBT and telechelic PIB-b-PBT were synthesized in the melt ${ }^{16,17}$. The PIB- $b$-PBT contained $30 \mathrm{wt} \%$ PIB with a block length of $1500 \mathrm{~g} \mathrm{~mol}^{-1}$. The PIB contained an unsaturated group at its chain end. The inherent viscosity ${ }^{16}$ of a $1 \%$ solution of the polymer in phenol/1,1,2,2-tetrachloroethane $(50 / 50)$ at $25^{\circ} \mathrm{C}$ is $1.69 \mathrm{dl} \mathrm{g}^{-1}$.

Sample preparation for TEM. $\mathrm{NaIO}_{4}$ (supplied by Merck) was dissolved in deionized water $\left(25^{\circ} \mathrm{C}\right) 1$ day before staining and kept in a refrigerator overnight. $\mathrm{RuO}_{2} \cdot x \mathrm{H}_{2} \mathrm{O}$ (supplied by Janssen) was added to the chilled $\mathrm{NaIO}_{4}$ solution $5 \mathrm{~min}$ prior to use. As $\mathrm{RuO}_{2} \cdot x \mathrm{H}_{2} \mathrm{O}$ began to dissolve, an olive green solution was formed. It was found that the quicker the container was filled and closed the longer the solution stayed green. It was established that if these precautions were taken the liquid stayed green at room temperature for up to $72 \mathrm{~h}$ and at $75^{\circ} \mathrm{C}$ for up to $4-5 \mathrm{~h}$.

The polymer samples were dissolved in a mixture of 1,1,2,2-tetrachloroethane and phenol $(1: 1 \mathrm{~mol} / \mathrm{mol})$ to obtain a $0.5 \mathrm{wt} \%$ solution. Glass slides were dipped in the solution. The solvent was evaporated at $160^{\circ} \mathrm{C}$ to leave thin films which were first floated off onto the water surface and then transferred to microscope grids. Some thin films on glass slides and other films on microscope grids were exposed to $\mathrm{RuO}_{4}$ vapour. The samples were stained in glass-covered dishes at room temperature for $15 \mathrm{~min}$ (ref. 18 ), 1, 3 and $5 \mathrm{~h}$ and at $75^{\circ} \mathrm{C}$ (above the glass transition of PBT) for $3 \mathrm{~h}$.

Melt pressed bars were obtained by heating dry PIB-b-PBT in a press to $250^{\circ} \mathrm{C}$ and cooling under 


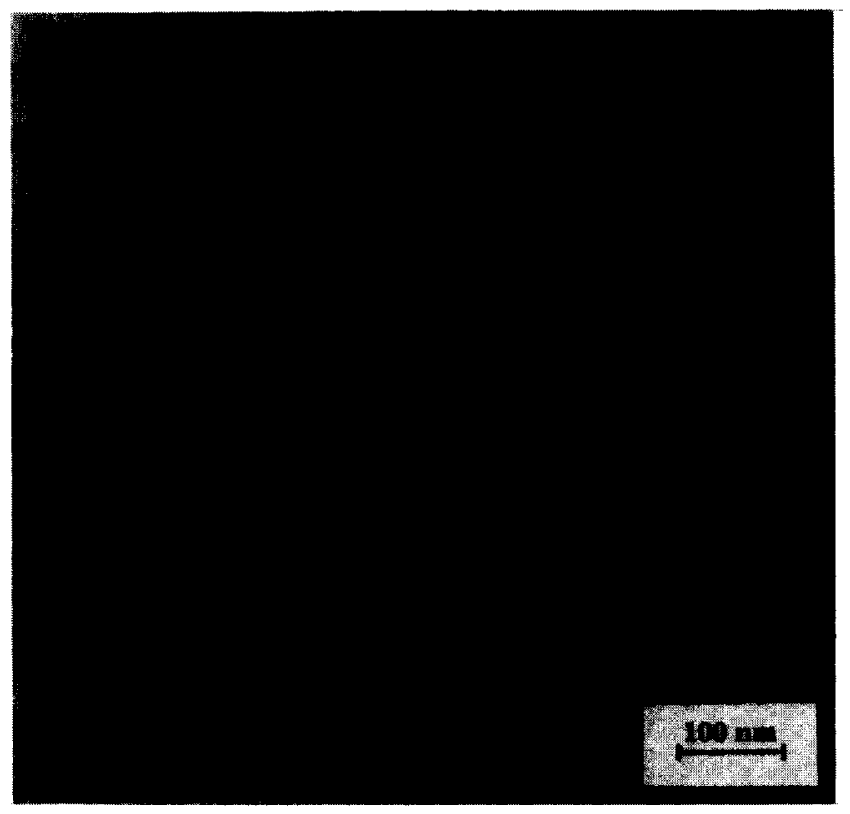

Figure 1 Electron micrograph of PBT film stained with $\mathrm{RuO}_{4}$ for $1 \mathrm{~h}$ at room temperature

pressure at $\sim 20^{\circ} \mathrm{C} \min ^{-1}$. For structure analysis the middle sections of the melt pressed bars were trimmed with a razor blade to form a trapezoidal top with a cutting surface of $100 \mu \mathrm{m}^{2}$. A LKB Nova ultramicrotome fitted with a diamond knife was used for sectioning. The cutting speeds were in the range of $5-20 \mathrm{~mm} \mathrm{~s}^{-1}$.

Cryogenic sectioning was conducted with the specimen cooled down to -100 to $-110^{\circ} \mathrm{C}$ and the knife cooled to -50 to $-70^{\circ} \mathrm{C}$. Unfortunately the sections obtained were statically charged and difficult to handle. The sections were removed from the knife edge with an eyelash and then transferred to a $2 \mathrm{~mm}$ wide wire loop filled with a concentrated aqueous sucrose solution. The sections with the sucrose drop were placed on the grids and the sucrose washed away. The slices were stained in $\mathrm{RuO}_{4}$ vapour for $16 \mathrm{~h}$ at room temperature.

Staining the trimmed sample first and then sectioning at room temperature was also used. With this method the sections were much easier to handle and sections with the right contrast could be chosen for analysis. Staining of the trimmed samples was carried out by suspending the bar in aqueous $\mathrm{RuO}_{4}$ solution for $24 \mathrm{~h}$ at room temperature or $16 \mathrm{~h}$ at $75^{\circ} \mathrm{C}$ (twice refreshed).

Transmission electron microscopy. The micrographs of the films were taken with a Jeol JEM-200CX transmission electron microscope operated at an accelerating voltage of $200 \mathrm{kV}$. The image wobbler was used for focusing at calibrated magnifications of $\times 50000$ or below.

\section{Results and discussion}

$P B T$. (1) Film. On the unstained solution cast PBT films only a vague structure could be observed. If stained for $1 \mathrm{~h}$ at room temperature a spherulitic structure becomes visible (Figure 1) and the lamellae are 11-13 nm thick. Staining for longer times or at higher temperature $\left(75^{\circ} \mathrm{C}\right)$ gave similar results.

(2) Melt pressed. With cryogenic sectioning of melt pressed samples it was very difficult to obtain smooth slices. A lamellar structure could be observed but the overall quality of the images was not so good as for the films. Neat sections could be obtained by cutting stained bars at room temperature. If the bars are stained for $15 \mathrm{~h}$ at $75^{\circ} \mathrm{C}$ the depth of staining is $1.5-2.5 \mu \mathrm{m}$. Good quality images could be obtained from a depth of $1.4 \mu \mathrm{m}$. The edges of the slices were usually damaged by the oxidizing effect of $\mathrm{RuO}_{4}$. The lamellae of the melt pressed samples are $9-10 \mathrm{~nm}$ thick.

$P I B$-b-PBT (30/70). (1) Film. PIB-b-PBT-cast film could be stained at room temperature in $15 \mathrm{~min}$ (Figure 2). Staining for longer times or at higher temperature $\left(75^{\circ} \mathrm{C}\right)$ gave similar results. The structure of the block copolymer is spherulitic with $9-10 \mathrm{~nm}$ thick lamellae. The observed structure is the same as for polyetherester ${ }^{19,20}$ and polyetheramide ${ }^{21,22}$ block copolymers. At lower magnifications dispersed droplets $(0.6-7 \mu \mathrm{m})$ with a weaker contrast were observed. This means that in these films next to a lamellae structure of the block copolymer a macro dispersed phase is also present.

(2) Melt pressed. The melt pressed samples could best be sectioned at room temperature after staining at room temperature. Staining at $75^{\circ} \mathrm{C}$ is also possible.

The structure in the melt pressed samples is also lamellar (Figure 3a). The lamellae are the least stained areas and they are most probably the crystalline PBT phase. With d.s.c. it was found that the heat of melting did not change with staining, suggesting that the crystalline phase was not stained. The lamellae are stacked in prespherulite/sheaf-like structures which seem to be twisted. The lamellar spacing is either very small $(2-3 \mathrm{~nm})$ or relatively large $(8-14 \mathrm{~nm})$. The very small spacing was seen as an 'edge on' view and the larger spacing as a 'tilted' view of a lamella. At other places bundle-like structures were visible (Figure $3 b$ ). The bundles are $100-600 \mathrm{~nm}$ and are positioned at different angles to the cut view plane. These bundles seem to consist of a matrix with rod-like unstained phases with thicknesses of 3-6 nm and heavily stained regions (spheres 3-6 nm). At the boundaries between the bundles

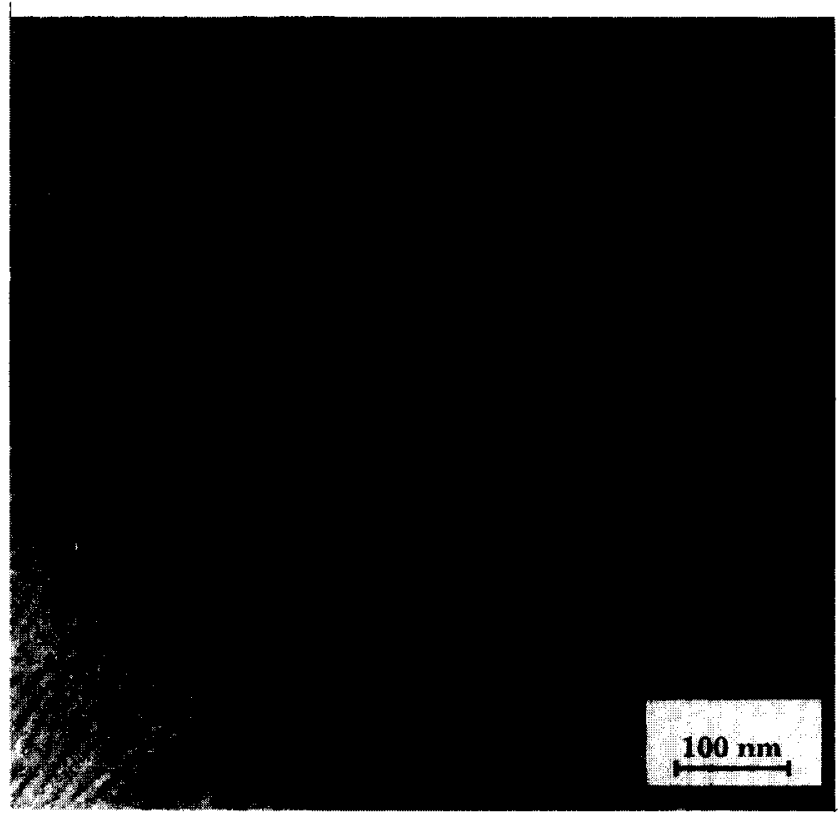

Figure 2 Electron micrograph of PIB- $b$-PBT film stained with $\mathrm{RuO}_{4}$ for $15 \mathrm{~min}$ at room temperature 

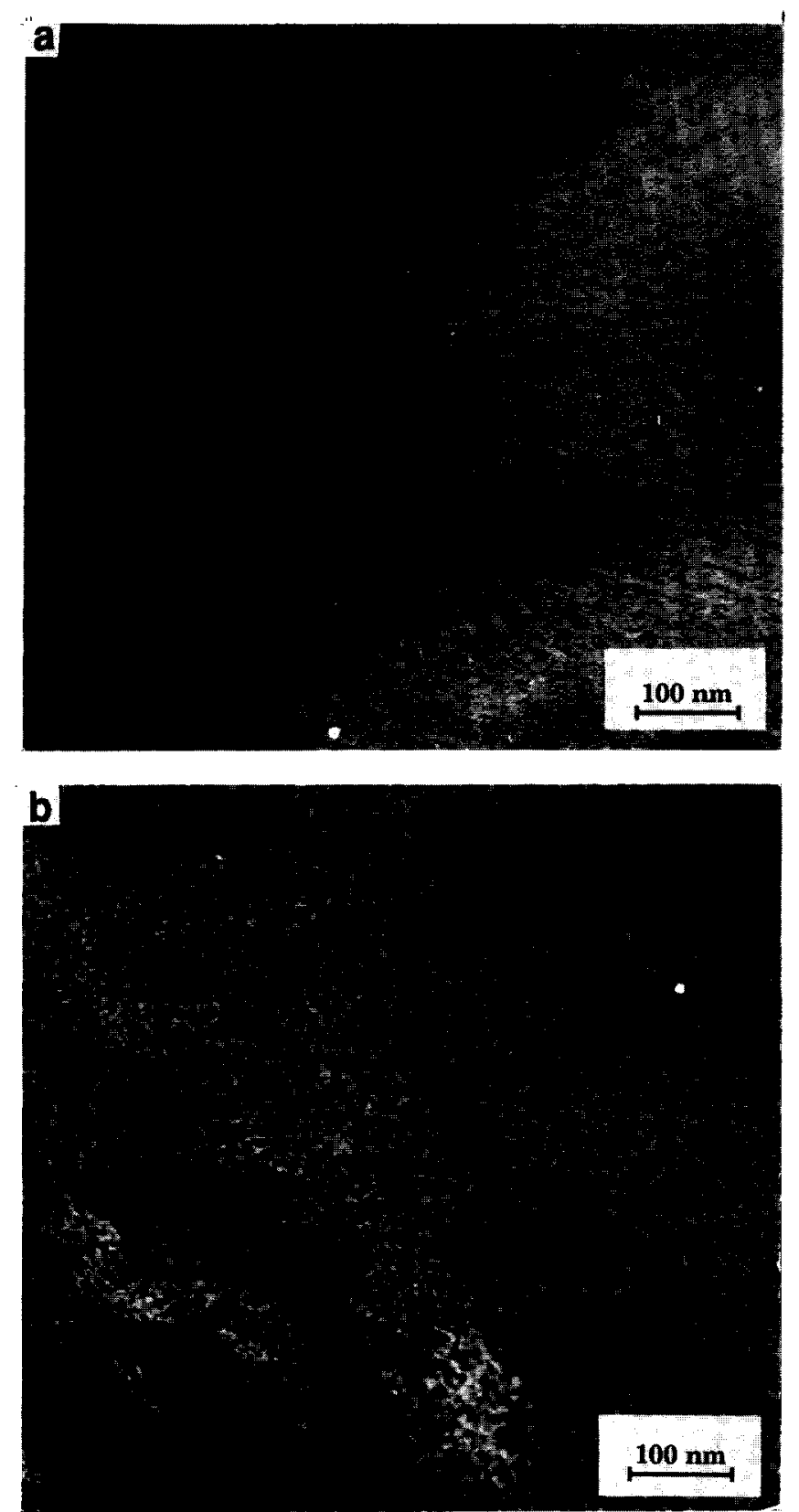

Figure 3 Electron micrographs of different regions in a PIB- $b$-PBT melt pressed sample first stained with $\mathrm{RuO}_{4}$ for $24 \mathrm{~h}$ at room temperature and then microtomed: (a) lamellae visible; (b) bundle-like structures visible

the concentration and size of the heavily stained material is higher. The unstained material is thought to be crystalline PBT and the heavily stained regions PIB.

\section{Conclusions}

The $\mathrm{RuO}_{4}$ staining technique was applied to PBT and PIB- $b$-PBT for morphological studies by TEM. Effective staining at room temperature is possible. For bulk samples it is preferable to stain the sample before microtoming at room temperature.

The structure of PIB- $b$-PBT (30/70) solution cast films is spherulitic with $9-10 \mathrm{~nm}$ thick lamellae. In some areas large scale phase separation takes place.

The melt pressed sample had a less well developed spherulitic structure and the lamellae seem to be twisted. In some places a bundle-like structure was observed with domain sizes of $100-600 \mathrm{~nm}$ where the PIB phase was present as 3-6 nm diameter microspheres.

\section{Acknowledgement}

This work is part of the research programme of the University of Twente and was financially supported by the Netherlands Innovative Research Programme for Polymers (IOP).

\section{References}

1 Legge, N. M., Holden, G. and Shroder, H. E. 'Thermoplastic Elastomers', Hanser Publisher, Munich, 1987

2 Walch, E. and Gaymans, R. J. Int. Rubber Conference, May 1990, Paris, Prepr. p. 88

3 Walch, E. and Gaymans, R. J. to be published

4 Kato, K. J. Electron Microsc. 1965, 14, 220

5 Kato, K. Polym. Eng. Sci. 1967, 7, 38

6 Sawyer, L. S. and Grubb, D. T. 'Polymer Microscopy', Chapman and Hall, London, 1989, p. 95

7 Trent, J. S., Scheinbeim, J. S. and Couchman, P. R. Macromolecules 1983, 16, 589

8 Trent, J. S. Macromolecules 1984, 17, 2930

9 Sano, H., Usami, T. and Nakagawa, H. Polymer 1986, 27, 1497

10 Froehling, P. E. and Pijpers, A. J. J. Polym. Sci. Polym. Phys Edn 1987, 25, 947

11 Chen, S., Cao, T. and Jin, Y. Polym. Commun. 1987, 28, 314

12 Foks, J., Janik, H. and Pohl, M. Eur. Polym. J. 1991, 27, 729

13 Schrader, S., Li, X., Guo, F. Lin, Y., Lup, J. and Xu, D. Makromol. Chem., Rapid Commun. 1988, 9, 597

14 Li, C. and Cooper, S. L. Polymer 1990, 32

15 Montezinos, D., Wells, B. G. and Burns, J. L. J. Polym. Sci., Lett. Edn 1985, 23, 421

16 Walch, E. and Gaymans, R. J. in preparation

17 Walch, E. and Gaymans, R. J. Polymer submitted

18 Howel, B. and Reneker, D. H. J. Appl. Polym. Sci. 1990, 40, 1663

19 Cella, R. J. J. Polym. Sci. Symp. 1973, 42, 727

20 Buck, W. H., Cella Jr., R. J., Gladding, E. K. and Wolfe, J. R. J. Polym. Sci. Symp. 1974, 48, 47

21 Perego, G., Cesari, M. and Della Fortuna, G. J. Appl. Polym Sci. 1984, 29, 1141

22 Perego, G., Cesari, M. and Vitali, R. J. Appl. Polym. Sci. 1984, 29, 1157 